\title{
Structural monitoring of an integral bridge in South Africa
}

Sarah A. Skorpen PhD, CEng, MIStructE, PrEng

Senior Lecturer, Department of Civil Engineering, University of Pretoria,

Pretoria, South Africa (Orcid:0000-0003-4151-2179) (corresponding

author: sarah.skorpen@up.ac.za)

Elsabe P. Kearsley PhD, PrEng

Professor, Department of Civil Engineering, University of Pretoria, Pretoria, South Africa (Orcid:0000-0003-0458-8908)
Chris R. I. Clayton PhD, CEng

Emeritus Professor of Infrastructure Engineering, Southampton University, Southampton, UK

Edwin J. Kruger BSC Eng, PrEng, CEng

Bridge Network Manager, The South African National Roads Agency SOC Ltd, Pretoria, South Africa

This paper gives an overview of almost 3 years of monitoring data obtained from instrumentation installed in a $90 \mathrm{~m}$ long reinforced concrete integral bridge in South Africa. The main objective of this structural monitoring project was to assess the effect of environmental factors on integral bridge abutment movement, with specific focus on thermal effects. The data obtained from the instrumentation enable designers to compare real and assumed effective bridge deck temperatures, earth pressures and abutment movements. Analysis of the data seems to indicate that the deck cross-sectional shape (defined as the ratio of surface area to the cross-sectional area) has a significant effect on the effective bridge deck temperature, abutment movement and earth pressure.

\author{
Notation \\ $A_{1} \quad$ deck cross-sectional area 1 \\ $A_{2} \quad$ deck cross-sectional area 2 \\ $L \quad$ bridge deck length \\ $R \quad$ horizontal reaction force on integral bridge footing \\ $T \quad$ deck temperature \\ $T_{1} \quad$ temperature of area 1 \\ $T_{2} \quad$ temperature of area 2 \\ $T_{\mathrm{e}} \quad$ effective deck temperature \\ $\alpha \quad$ coefficient of thermal expansion of concrete
}

\section{Introduction}

Over the last few years, structural monitoring has increasingly become the norm on large-scale, significant structures. In particular, new bridges with large spans often have a structural health monitoring system installed to help bridge authorities maintain and assess the condition of the bridge. There is also scope for structural monitoring of smaller-scale bridge structures such as integral bridges, where the structural behaviour during construction and service life remains poorly understood. As integral bridge decks become ever longer and working environmental conditions become harsher, there is a need for monitoring and development of design tools to support the use of this type of bridge.

Integral bridges are favoured by bridge authorities and road agencies because they eliminate the use of bearings, providing a simpler form of construction, with reduced maintenance costs. Published integral abutment bridge (IAB) research mostly focused on the behaviour of IAB substructures (Huang et al., 2008; Petursson and Kerokoski, 2013; Pugasap et al., 2009), and as a result, the design limit states considered by many road authorities are largely based on substructure considerations, usually as a function of soil properties at the abutment and pile foundation. This focus has been motivated by the significant increase in substructure demands for integral construction.
Recent research indicates that a better understanding of the bridge deck behaviour can benefit integral bridge designers. LaFave et al. (2016) showed that integral abutment construction also affects superstructure behaviour and demands and that superstructure properties can directly influence substructure behaviour. Parametric studies by Kim and Laman (2010) indicate that the bridge deck factors with the most significant influence on the structure behaviour are the deck length and coefficient of thermal expansion of the deck material. England et al. (2000) showed that smaller bridge deck thermal movements result in lower lateral earth pressures and reduced settlement of the fill behind the abutment. Understanding the effect of changes in deck temperature is thus crucial to the efficient design of durable integral bridges. While temperature-induced forces in conventional jointed bridge structures are often negligible, as the thermal movement is accommodated at the expansion joints, integral bridges cannot be designed without taking thermal movement into account. Work done by Elbadry and Ghali (1983), Emerson (1976) and Black et al. (1976) on reinforced concrete decks shows that the changes in effective bridge deck temperature are dependent on the ratio of the deck cross-sectional area to the deck width. The response of any structure to environmental climatic variation is dependent on the structure geometry and material.

\section{Bridge deck temperatures}

Changes in the ambient shade temperature and solar radiation result in changes to the bridge deck temperature. In reinforced concrete decks, both the low thermal conductivity of concrete and variation in the depth of the deck across its width have a significant effect on the temperature variation in the deck. The temperature variation in the deck affects the effective deck temperature, which governs the change in the length of the deck due to temperature variation. The effective bridge deck temperature is defined by Emerson (1973) and Roeder (2003) as the weighted average bridge deck temperature. It is calculated as the sum of the product of the area between bridge deck cross- 
section isotherms and their mean temperatures divided by the total area of the cross-section of the bridge deck. It is often difficult to locate the isotherms exactly, and an approximation can be made by dividing the deck cross-section into areas. If a bridge is constructed from a homogeneous material, the effective deck temperature may be calculated with the following equation:

1. $T_{\mathrm{e}}=\left(\frac{A_{1} T_{1}+A_{2} T_{2}}{A_{1}+A_{2}}\right)$

where $A_{1}$ is deck cross-sectional area $1, A_{2}$ is deck cross-sectional area 2, $T_{1}$ is the temperature of area 1 and $T_{2}$ is the temperature of area 2 .

Black et al. (1976) and Emerson (1976) compared the daily changes in effective bridge deck temperature for bridge decks of various thicknesses. Black et al. (1976) suggested that the daily range of effective bridge deck temperature can be related to the area of the deck cross-section per unit width of the deck. This work was continued by Emerson (1976), who selected various concrete bridge deck cross-sections and for each cross-section calculated the temperature distribution and maximum effective temperature using the same theoretical input data of solar radiation and shade temperature and the same starting temperature. Figure 1 shows the effect of the area of the cross-section per unit width of the deck on the daily range of effective bridge deck temperatures and compares them with the original calculations done by Black et al. (1976). A summer ambient temperature change from 18 to $38^{\circ} \mathrm{C}$ was used, as well as a maximum midday solar radiation of $900 \mathrm{~W} / \mathrm{m}^{2}$ and a $14 \mathrm{~h}$ solar day. The deck marked as number 3 was a $2.15 \mathrm{~m}$ thick section, and the deck marked as number 16 was a $0.15 \mathrm{~m}$ thick section. The correlation between the daily change in the effective bridge deck temperature and the area of the deck cross-section per unit width of the deck is evident. It is clear that increasing the deck cross-section

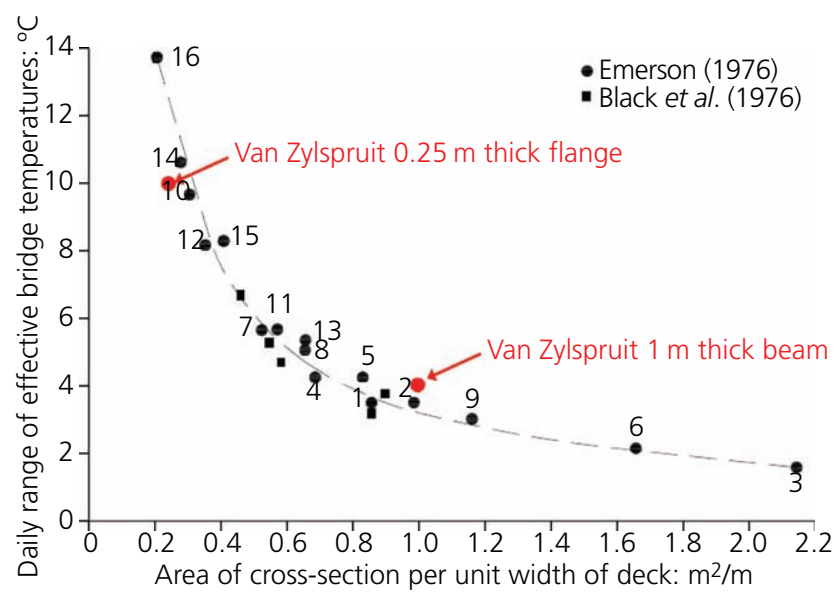

Figure 1. Effect of the deck cross-sectional area per unit width on the daily range of effective bridge deck temperatures (adapted from Emerson (1976)) per unit width ratio increases the thermal inertia of the section and this reduces thermal movement.

The change in the temperature of an integral bridge deck results not only in a reaction force applied to the top of the abutment but also in the movement of the abutment. The movement of the abutment causes changes in the earth pressure behind the abutment.

Robberts (2003) used work and energy principles to solve the horizontal reaction forces $(\Delta R)$ on single-span portal framed structures with hinged supports. The portal frames were subjected to cyclic thermal changes where material properties and loads (i.e. earth pressure) varied with time and change in the seasonal effective deck temperature $\left(\Delta T_{\mathrm{e}}\right)$. This study identified span length and abutment height as having the biggest influence on the abutment reaction, while the stiffness properties of the members had a lesser influence. Temperature variations were identified as the parameter with the most uncertainty, as design values in codes are usually limiting values based on the maximum possible temperatures that can occur. The influence of the beam (i.e. deck) cross-section on the thermal inertia of the deck was not discussed, and the $\Delta T$ values used in the analyses were assumed. Solar radiation was also discussed, but it seemed not to be included in the models. When using an assumed seasonal temperature change of $\Delta T=50^{\circ} \mathrm{C}$, the largest values for $\Delta R$ occurred when the span length $L$ becomes large and the abutment height $H$ becomes shallow. The temperature change in these calculations was, however, not based on measured values, and it would be valuable to know what the practical range of actual deck temperature changes is.

\section{Structural monitoring of an integral bridge in South Africa}

The Van Zylspruit Bridge is located on the South African National Roads Agency Limited (Sanral) National Route N1 in central South Africa, about $600 \mathrm{~km}$ South of Pretoria, near the town of Trompsburg. This is an area known for its dry harsh climate with both high and low temperatures. The bridge is $90 \mathrm{~m}$ long (see Figure 2 for spans) and is orientated in the north-south direction. It was constructed from reinforced concrete, and the deck is fully integral with the piers and abutments. The deck section varies significantly in depth with the flange thickness being a quarter of the beam thickness $(1000 \mathrm{~mm})$. The deck comprises two $2000 \mathrm{~mm}$ wide outside flanges that vary in depth from 250 to $350 \mathrm{~mm}$; two $2000 \mathrm{~mm}$ wide and $1000 \mathrm{~mm}$ deep beams; and a $250 \mathrm{~mm}$ thick, $4000 \mathrm{~mm}$ wide central flange that connects the beams. Figure 3 shows the deck cross-section. This bridge is currently the longest fully integral bridge built in South Africa and was instrumented by Sanral and the University of Pretoria in an effort to promote the design and construction of reduced-maintenance bridge structures in South Africa.

Extensive instrumentation was installed in the bridge during construction to measure the environmental effects on the structure, and numerous samples were taken to determine the material properties. The data from this instrumentation have been logged continually from the construction phase onwards. The instrumentation 


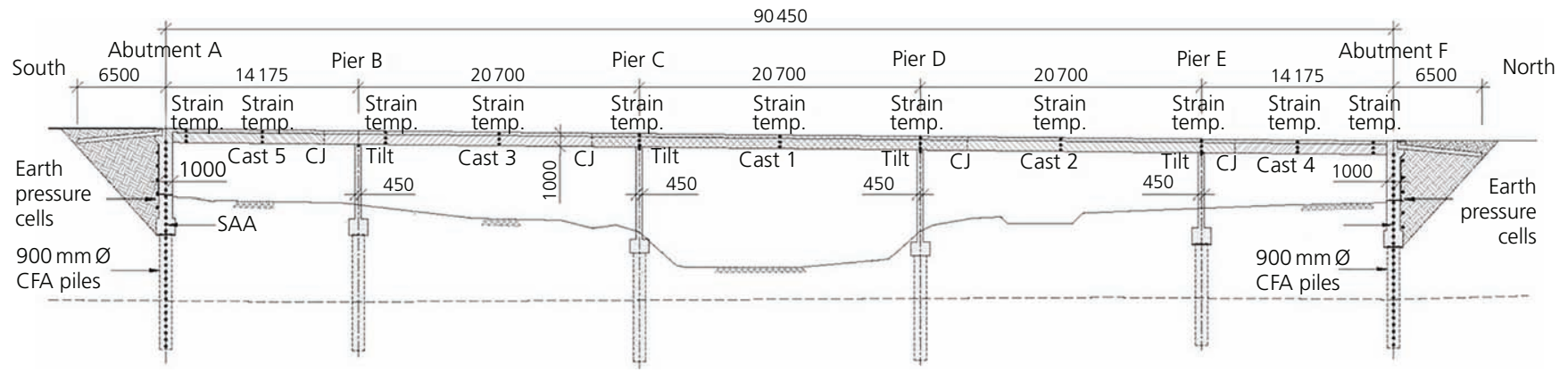

Figure 2. Typical bridge long section showing sensor positions. Dimensions are in mm. CFA, continuous flight auger; SAA, shape accel array

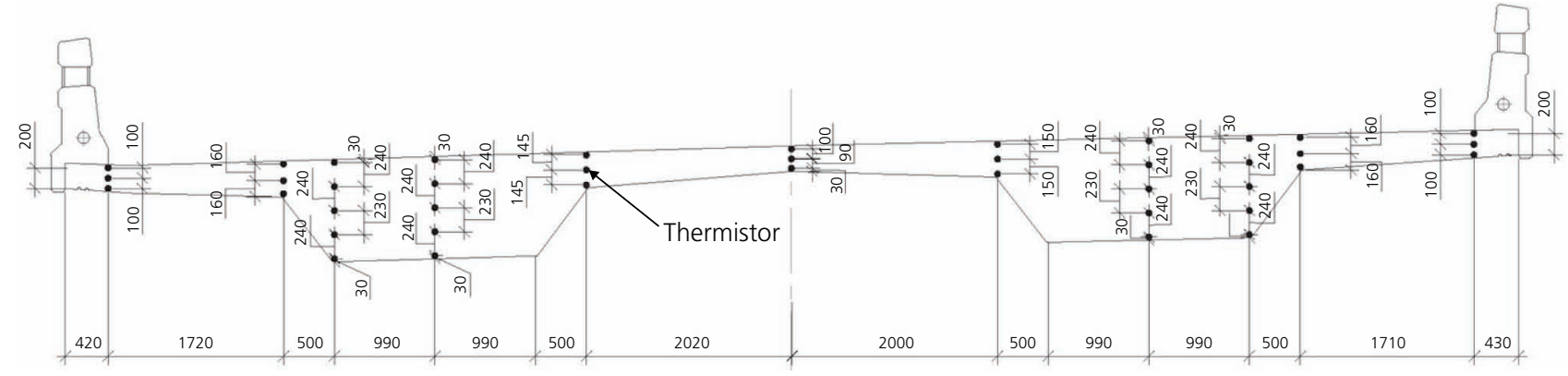

Figure 3. Typical bridge cross-section through the deck showing variation in deck thickness and positions of thermistors in span $A B$. Dimensions are in $\mathrm{mm}$

selection was specific for long-term, static monitoring. Vibrating wire instrumentation was deemed to be best suited for static measurements and long-term applications, and this was the reason for installing this type of sensor for the strain gauges and earth pressure cells. The temperature was measured with thermistors. The logging set-up was designed so that the bridge deck could be continually monitored during construction. Once all the sensors had been embedded in the deck, the sensor wiring was reconfigured for the final phase logging system. This meant that the system had to be shut down for about 2 months in July and August 2016 while this was under completion.
This instrumentation includes (see Figure 2 for positioning along the length of the bridge) the following:

- Forty-one thermistors (see Figure 3 for positioning of thermistors) installed in the deck cross-section of span AB.

- One hundred ten vibrating wire strain gauges (each of which contains a built-in thermistor), with ten strain gauges installed in the deck section (see Figure 4 for positioning of strain gauges) not only at the centre of each span but also over each pier, measuring strain in the longitudinal direction.

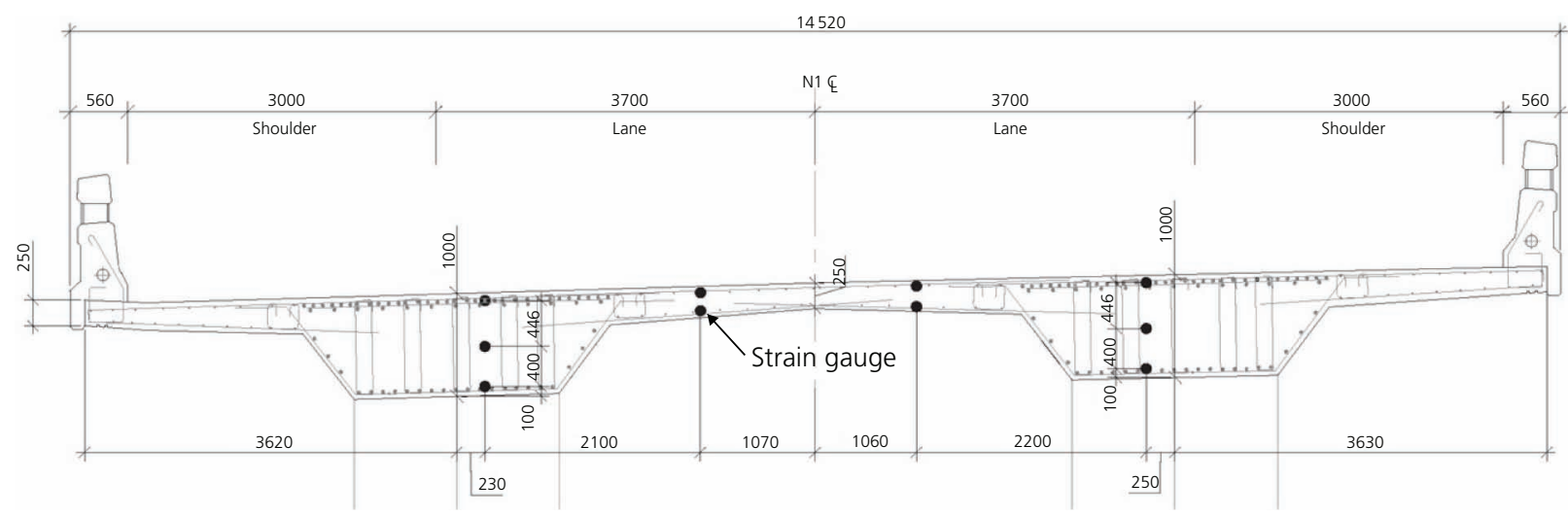

Figure 4. Typical bridge cross-section showing strain gauge positions. Dimensions are in $\mathrm{mm}$ 
- Ten vibrating wire earth pressure cells installed behind each abutment for monitoring earth pressure. The pressure cells were placed in recesses cast into the back face of the abutments to allow the pressure cell to sit flush with the face of the concrete. Because the abutment wall was fairly wide, half (five) of the cells were installed at $1 \mathrm{~m}$ depth intervals from the top of the pile cap in the centre of the wall and the other half (five) were installed $1 \mathrm{~m}$ from the outer edge of the wall. On the northern abutment, they were installed on the eastern outer edge, and on the south abutment on the western outer edge.

- A vertical shape accel array (SAA; a string of tiltmeters connected by $0.5 \mathrm{~m}$ long rigid links) at the centre of each abutment. The tiltmeters at the end of each link measure the tilt in the $x, y$ and $z$ directions, as well as the temperature. The string of tilt measurements can be used to calculate the relative movement and rotation of the abutment wall and piles, taking the base of the pile as the reference point. The northern abutment SAA is $11 \mathrm{~m}$ long with 22 rigid links, and the southern abutment SAA is $13 \mathrm{~m}$ long with 26 rigid links. A sketch of the abutment showing the relative positions of the SAA as well as the lateral earth pressure cells is shown in Figure 5.

It was considered prudent to ignore the symmetry of the structure and install instrumentation throughout the length and on both sides of

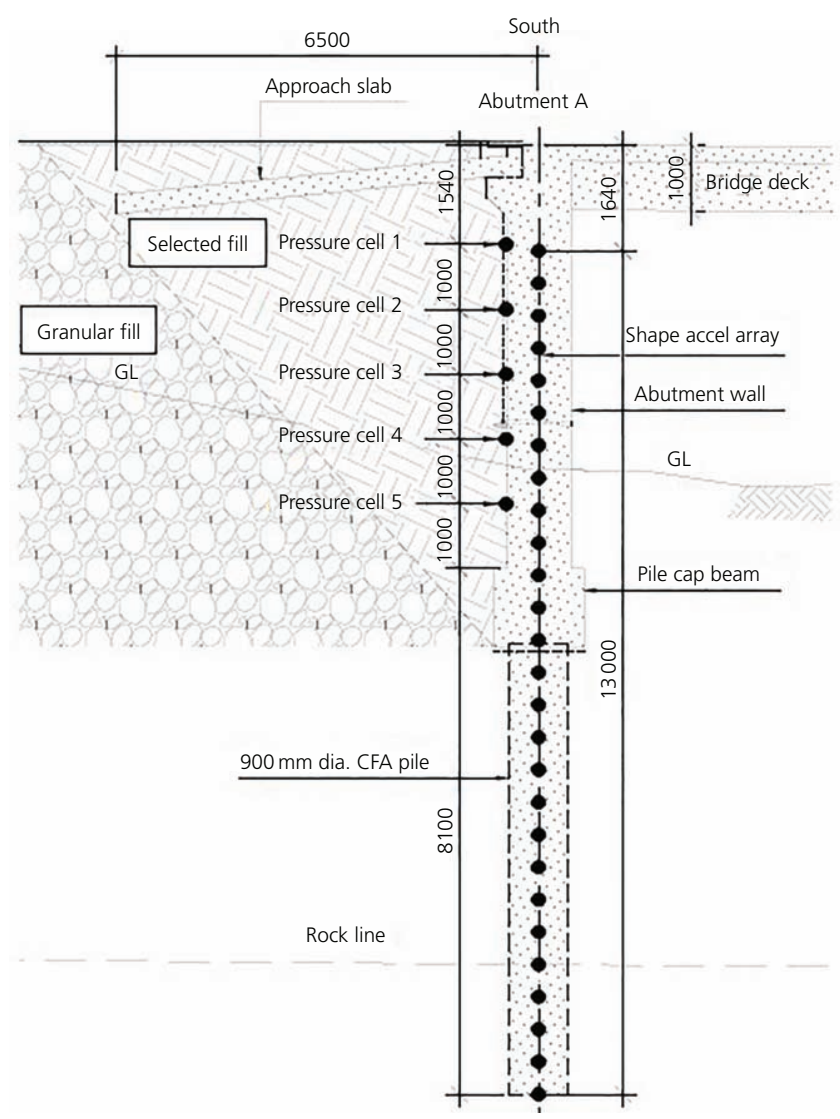

Figure 5. Instrumentation at the abutment. CFA, continuous flight auger; $\mathrm{GL}$, ground line the structure, which provided some necessary redundancy to the monitoring system. A special ruggedised cable was specified to eliminate breakages during the installation and concreting. This worked well, and no cable breakages occurred during the installation.

\section{Concrete properties}

A durability specification concrete was used for the bridge, with a specified 28-day compressive strength of $40 \mathrm{MPa}$. The durability specification required a minimum amount of cement in the concrete mix resulting in not only smaller pores in the concrete to prevent water ingress but also to provide significantly higher concrete strengths. The aggregate type used was dolerite, as it is well known that the type of aggregate plays an important role in the properties of the concrete. Samples were taken of the concrete during construction to determine the 28-day compressive strength, tensile strength, modulus of elasticity, coefficient of thermal expansion and shrinkage. A summary of the average measured concrete material properties of the specified concrete is shown in Table 1.

The coefficient of thermal expansion can vary in the concrete section and was a difficult material property to measure. A range of values were measured for this project varying from 8.5 to $9.75 \times 10^{-6} /{ }^{\circ} \mathrm{C}$ (consistent with concrete comprising dolerite aggregate) by heating and cooling a $250 \mathrm{~mm}$ diameter, $500 \mathrm{~mm}$ long concrete cylinder in a laboratory oven. A vibrating wire strain gauge (measuring strain as well as temperature) was cast longitudinally into the centre of the cylinder. After the cylinder had been dried, strain changes were recorded while the oven temperature was increased from 35 to $55^{\circ} \mathrm{C}$ in increments of $10^{\circ} \mathrm{C}$. Strains were allowed to stabilise for each temperature interval, and the temperature was then reduced in increments of $10^{\circ} \mathrm{C}$.

\section{Measured temperatures}

\subsection{Ambient temperature and solar radiation}

Ambient air temperature and solar radiation were measured with an HP1000 weather station during the bridge construction at the site office (approximately $1 \mathrm{~km}$ from the bridge site) from January 2015 up to March 2017 when the contractor left the site. Figure 6 shows the ambient temperature measured at the site office, indicated as the light grey plot. In August 2016, once the loggers had been placed in their permanent positions, a thermistor was installed under the deck to measure the ambient shade temperature (shown as the dark grey plot), and the temperature has been logged continually together with the rest of the bridge

Table 1. Average measured concrete properties

\begin{tabular}{|lc|}
\hline Concrete property & $\begin{array}{c}\text { Measured } \\
\text { value }\end{array}$ \\
\hline 28-day compressive cube strength, $f_{\mathrm{cu}}: \mathrm{MPa}$ & 60 \\
28-day split cylinder strength, $f_{\mathrm{ct}}: \mathrm{MPa}$ & 3.6 \\
28-day modulus of elasticity, $E_{\mathrm{c}}: \mathrm{GPa}$ & 37 \\
Coefficient of thermal expansion, $\alpha: \times 10^{-6} /{ }^{\circ} \mathrm{C}$ & $8.5-9.75$ \\
Total drying shrinkage, $\varepsilon_{\mathrm{sh}}-\mathrm{SANS} 50197-1: 2000$ & $800 \mu \varepsilon$ \\
(SABS, 2000) & \\
\hline
\end{tabular}




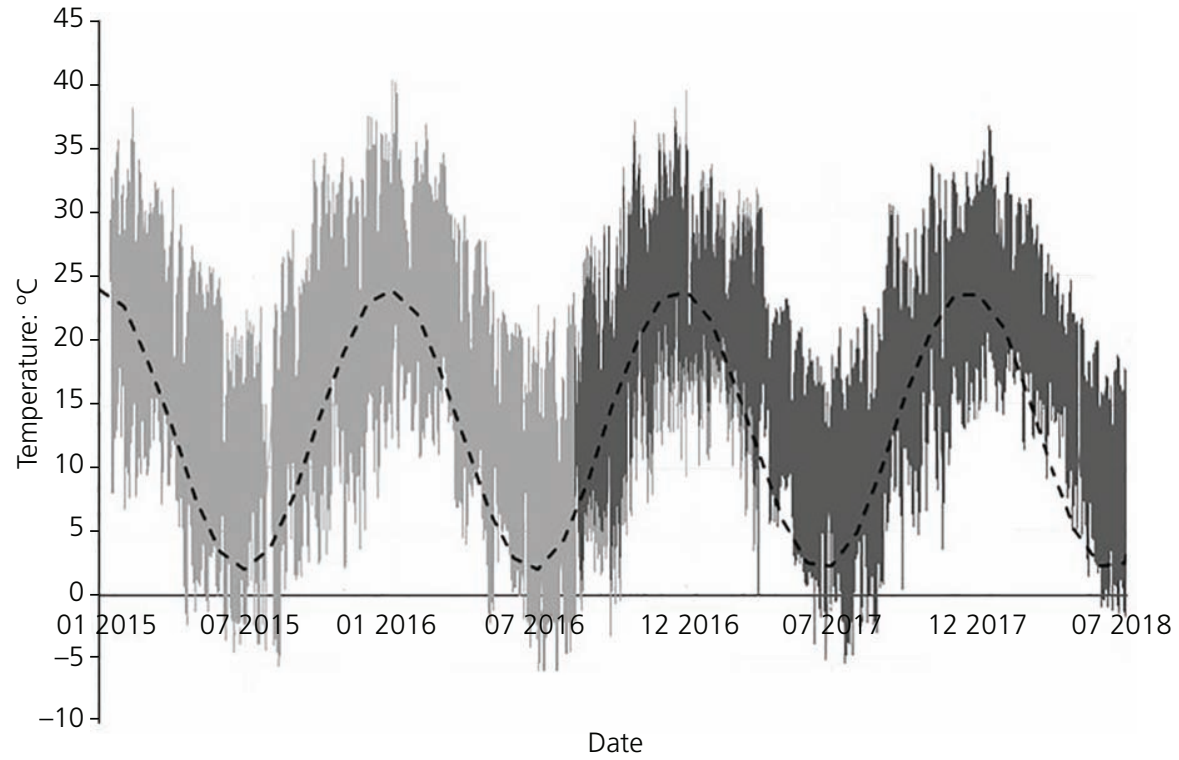

Figure 6. Measured shade temperature from January 2015 to July 2018

sensors. This graph shows a clear sinusoidal seasonal ambient temperature variation.

Based on temperatures measured at the bridge site from January 2015 to July 2018, the maximum shade temperature range was $48.2^{\circ} \mathrm{C}$, varying from a maximum of $40.3^{\circ} \mathrm{C}$ in summer (January 2016) to a minimum of $-7.9^{\circ} \mathrm{C}$ in winter (July 2016). The average shade temperature in summer was $23.9^{\circ} \mathrm{C}$, and $10.9^{\circ} \mathrm{C}$ in winter. A summary of the average temperatures and maximum, minimum and daily temperature ranges for the four seasons (averaged over the 4 months of each season) is given in Table 2.

In summer, the solar radiation reached a maximum of $1000 \mathrm{~W} / \mathrm{m}^{2}$ at midday. The length of a solar day in midsummer was approximately $13 \mathrm{~h}$. In winter, the solar radiation peaked at $600 \mathrm{~W} / \mathrm{m}^{2}$ at midday, which was almost one-third less than the maximum radiation measured in summer. The length of a solar day in midwinter was about $11 \mathrm{~h}$. The solar radiation on a hot summer day was significantly higher than the solar radiation on a cold day; however, the daily range in ambient shade temperature was higher in winter than in summer. Figure 7 shows the measured solar radiation and ambient temperature measured on typical summer and winter days.

\subsection{Effective bridge deck temperature}

The most important aspect of bridge deck temperature with regard to integral bridges is the change in the effective bridge deck temperature (daily and seasonally) that causes the deck to move and, with that, the abutment and fill behind it. Figure 8 shows a histogram of the frequency distribution of the measured daily changes in the effective bridge deck temperature of the deck, as well as the change in effective flange $(250 \mathrm{~mm}$ thick) and beam $(1 \mathrm{~m}$ thick) temperatures.

Figure 8 shows a much larger daily temperature range for the thin flanges compared with that for the thick beams. The maximum measured daily temperature change of the flanges was $12.9^{\circ} \mathrm{C}$, compared with $6.5^{\circ} \mathrm{C}$ for the beams. The mean (average) daily change in effective temperature was definitely dependent on the thickness of the section. The difference in the mean effective temperature change of the beam was at least $3^{\circ} \mathrm{C}$ lower than that of the thin flanges. The trend observed in the measured daily change in the effective bridge deck temperature was consistent with work done by Black et al. (1976) and Emerson (1976) on the influence of the shape of the crosssection on the bridge effective temperature as shown in Figure 1. Emerson (1976) suggested that the effective bridge deck temperature is related to the area of the cross-section of the deck per metre width of deck. The measured changes in the effective deck temperature at

Table 2. Seasonal ambient temperatures

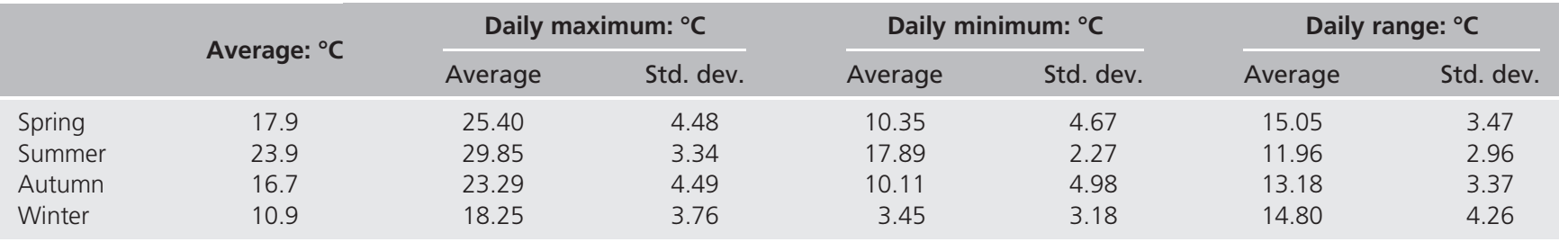

Std. dev., standard deviation 


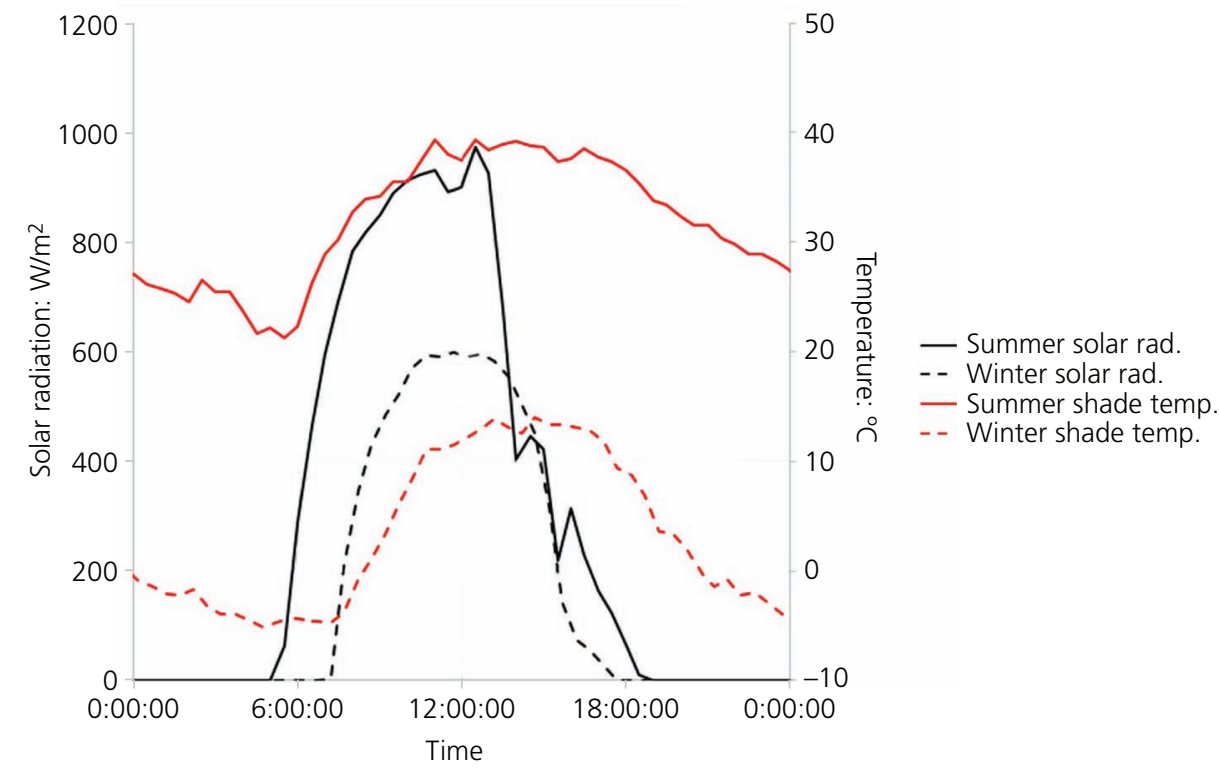

Figure 7. Solar radiation and ambient temperature on typical summer and winter days

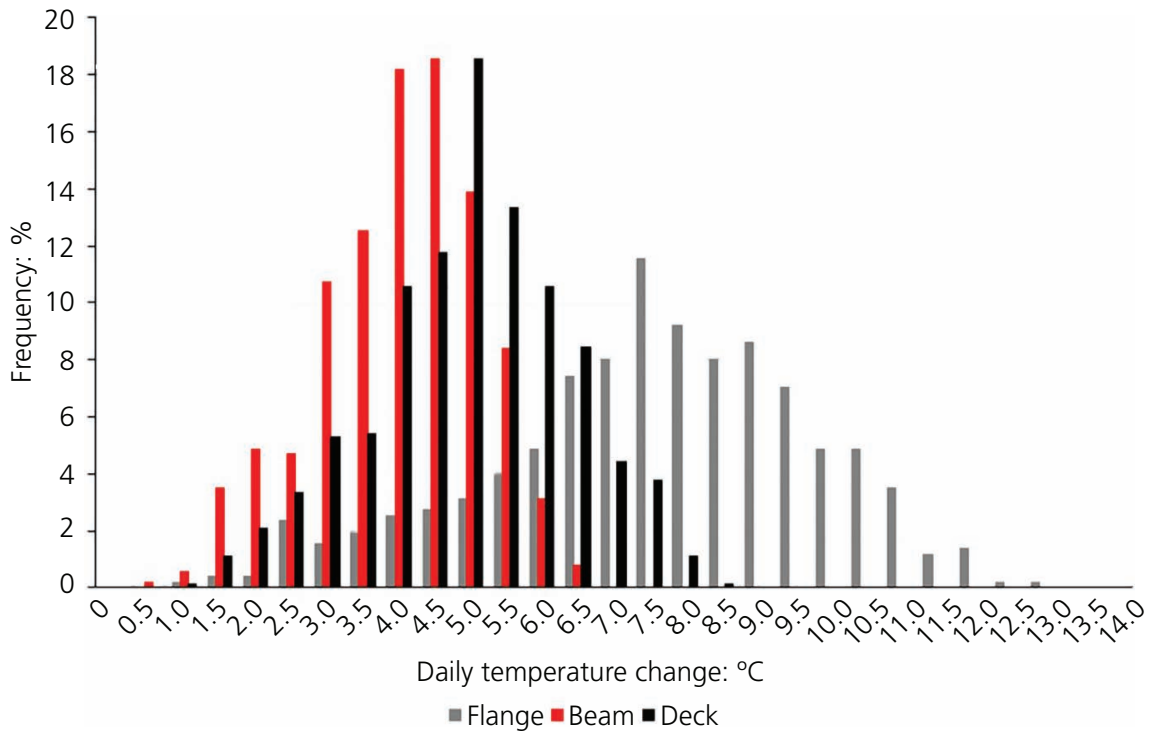

Figure 8. Histogram of the frequency distribution of the measured daily changes in effective bridge, flange and beam temperatures

the Van Zylspruit Bridge for a similar ambient temperature and solar radiation range as used by Emerson (1976) (i.e. ambient temperature change from 18 to $38^{\circ} \mathrm{C}$ was used, as well as a maximum midday solar radiation of $900 \mathrm{~W} / \mathrm{m}^{2}$ and a $14 \mathrm{~h}$ solar day) are shown in red in Figure 1, being a close match to the trend line.

The influence of the depth of the cross-section can also be seen in the seasonal change in effective deck temperature data. The maximum ranges for rolling 1 day, 3 days, 7 days, 1 month and 6 months were calculated for the entire deck, as well as the $250 \mathrm{~mm}$ thick central flange and the $1 \mathrm{~m}$ thick beams, which are given in
Table 3. The maximum change in the effective bridge deck temperature in 1 day was $8.3^{\circ} \mathrm{C}$ and over 6 months was $30.2^{\circ} \mathrm{C}$, which was compared with the change in effective beam and flange temperatures and as well as the maximum effective temperature ranges measured by Emerson (1973) in the UK. Higher daily and seasonal effective temperature changes were calculated for the thin flanges. There was a difference of $3.9^{\circ} \mathrm{C}$ in the seasonal effective temperature change between the flange and the beam.

The effective deck temperatures used in the calculations for Table 3 over a 2-year period are shown in Figure 9. The range 
Table 3. Highest recorded range (i.e. change) of effective bridge temperatures

\begin{tabular}{lccccc} 
& \multicolumn{5}{c}{ Maximum range of effective bridge temperature: ${ }^{\circ} \mathbf{C}$} \\
\cline { 2 - 6 } Type of construction & $\mathbf{1}$ day & $\mathbf{3}$ days & $\mathbf{7}$ days & $\mathbf{1}$ month & $\mathbf{6}$ months \\
\hline Concrete (Emerson, 1976) & 7.0 & 12.0 & 14.0 & 17.0 & 32.0 \\
Van Zylspruit deck & 8.3 & 12.9 & 13.8 & 17.9 & 30.2 \\
Van Zylspruit beam & 6.5 & 10.9 & 11.9 & 15.8 & 29.1 \\
Van Zylspruit flanges & 12.9 & 17.5 & 18.1 & 22.5 & 33.0
\end{tabular}

falls well within the design range based on the maximum and minimum design effective temperatures given in the South African bridge code, TMH7 (DOT, 1989). This range is significantly lower than the assumed seasonal temperature range of $50^{\circ} \mathrm{C}$ used by Robberts (2003).

\section{Heat flow modelling}

Besides solar radiation and ambient temperature, the other important parameters to consider when studying the heat flow and temperature change of a concrete bridge deck is the concrete conductivity and specific heat. To assess the importance of the heat flow parameters of the deck material on the change in the effective temperature of a cross-section, a number of heat flow finite-element models were analysed in the Abaqus software (2018) for a range of concrete conductivity and specific heat values and typical summer and winter day conditions. Different deck cross-sections, ranging from 0.25 to $2.00 \mathrm{~m}$ thick, were modelled, and the change in effective temperature was calculated.

A range of conductivity and specific heat values typically used in research were assessed (Branco and Mendes, 1993; Emerson, 1973; Larsson and Svensson, 2013; Priestly, 1978). Conductivity was varied from 1.5 to $2.5(\mathrm{~W} / \mathrm{m}) /{ }^{\circ} \mathrm{C}$, and specific heat values were varied from 700 to $1500(\mathrm{~J} / \mathrm{kg}) /{ }^{\circ} \mathrm{C}$. Higher specific heat was linked to concrete with a higher moisture content.

The heat flow models show that conductivity has a smaller influence on the change in effective temperature than specific heat. Figure 10 shows the influence of specific heat on the change in effective temperature in summer when the ambient temperature changes by $20^{\circ} \mathrm{C}$ (thermal loading as per the example by Emerson (1973)) when the conductivity is assumed to be $1.5(\mathrm{~W} / \mathrm{m}) /{ }^{\circ} \mathrm{C}$. It is clear that the lower the specific heat, the higher the change in temperature on any given day (i.e. less energy required to heat the deck). The measured results from Van Zylspruit on a day similar to this are comparable with the range of calculated values.

The trend of reduced effective temperature changes observed in decks with a higher thermal inertia (i.e. higher area of cross-section per unit width of the deck) was also still evident. The biggest daily temperature changes were calculated for a thin section with a low moisture content, and the smallest temperature changes in a thick section with a higher moisture content. The difference in the change in effective temperature was as much as $16^{\circ} \mathrm{C}$, indicating that the thermal inertia of a deck cross-section should be carefully considered when selecting a deck cross-section for an integral bridge.

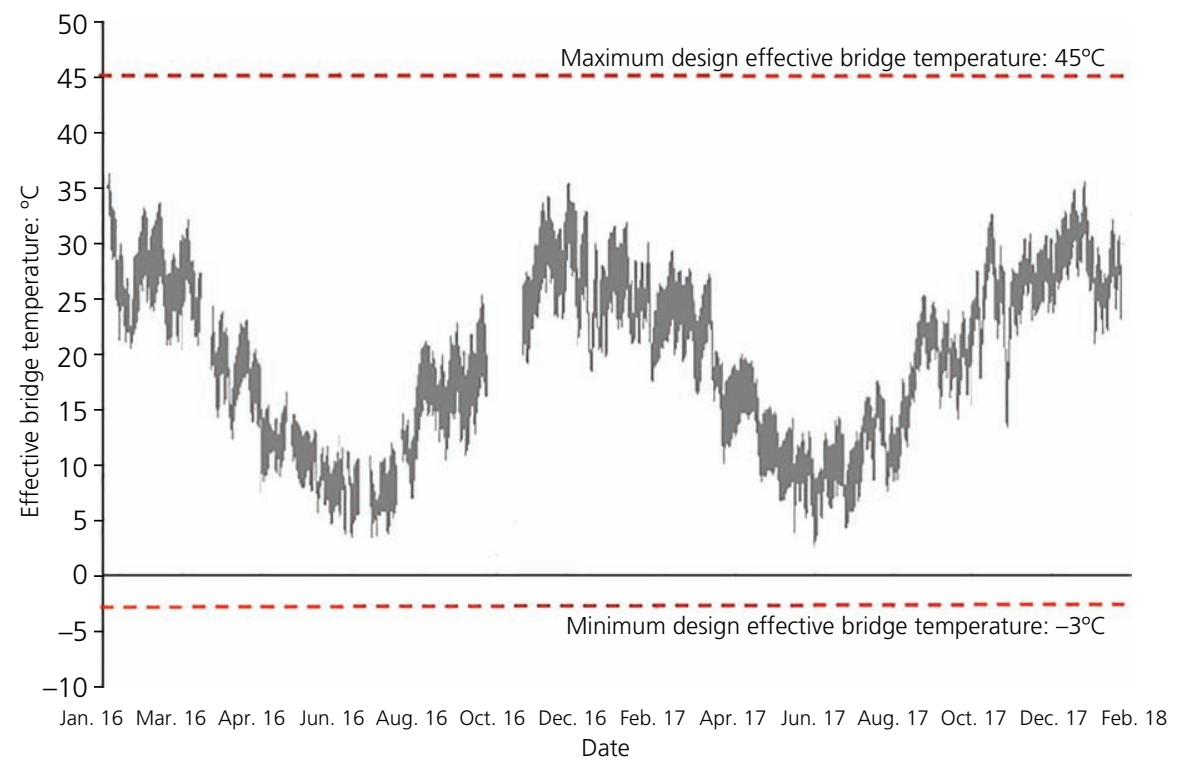

Figure 9. Effective bridge deck temperatures from January 2016 to February 2018 


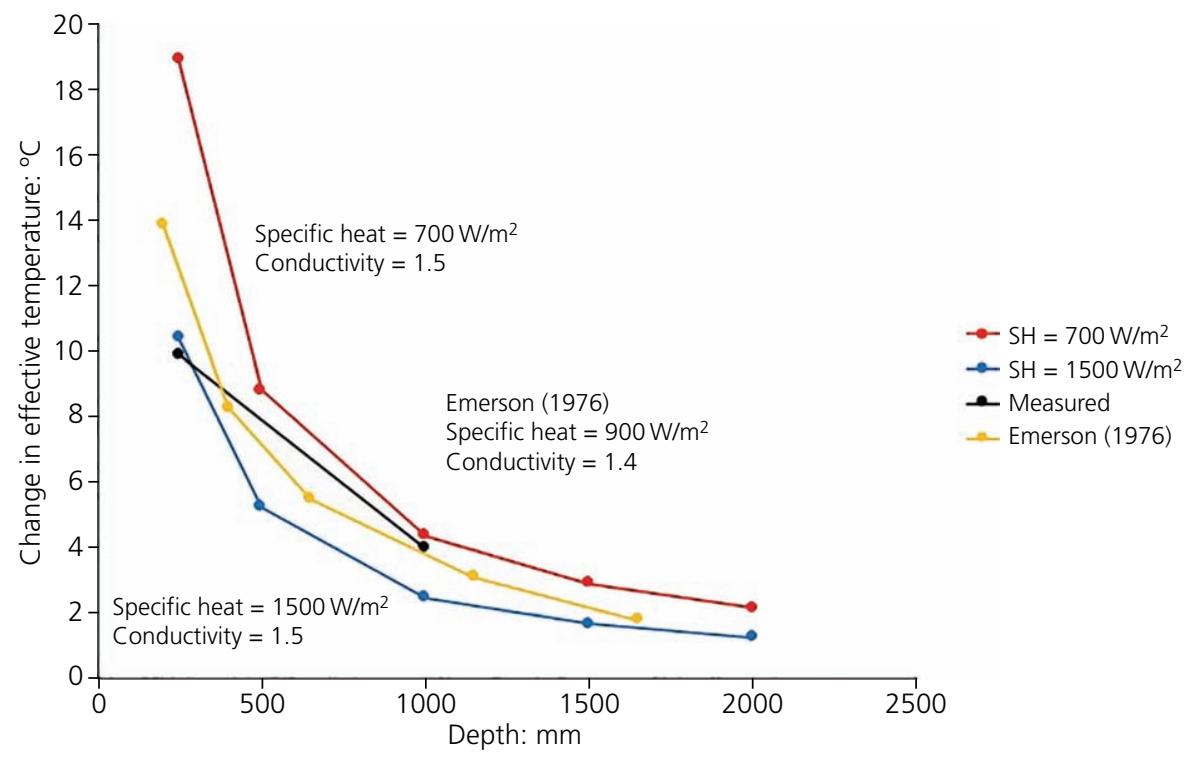

Figure 10. Daily change in the effective deck temperature compared with the area of the cross-section per unit width of the deck for different specific heat values

While it is acknowledged that the seasonal effective range is very important for the design of integral bridges, daily temperature ranges also have a significant impact on the behaviour of these bridges. England et al. (2000) concluded that daily movements (assumed to be one-quarter to one-tenth of seasonal movements) induced more soil densification and deformation. In comparison with values for seasonal movements alone, the inclusions of daily abutment wall movements increased the settlements adjacent to the wall by $100 \%$ and the heave away from the wall by $150 \%$. When more strain (i.e. a longer bridge and/or increase in the change in effective bridge temperature) was imparted to the soil during a double-cycle operation, more granular flow occurred, resulting in increased settlement adjacent to the abutment wall.

\section{Abutment movement}

In an integral bridge, once the deck has been cast monolithically with the abutment, the abutment movement is governed by the deck. The thermal action of the deck on the abutment causes the abutment to move outwards, as the deck expands, and inwards, as the deck contracts. To verify the deck action onto the abutment, the movement of the top of the Van Zylspruit abutment was plotted using the north abutment SAA data. The relative movement of the SAA tiltmeters (spaced at $0.5 \mathrm{~m}$ ) was plotted with respect to the base of the instrument, which was at the bottom of the central abutment pile. Figure 11 shows the thermal movement of the top of the north abutment from October 2016 up until August 2018. As October 2016 was almost 10 months after the completion of the deck, the shrinkage movement was assumed to be negligible for this graph. The seasonal cyclic nature of the movement of the abutment can be clearly seen. The average seasonal thermal movement was from +5.5 to $-5.5 \mathrm{~mm}$ at each abutment (i.e. a total of $11.0 \mathrm{~mm}$ movement at each abutment).
The measured movement at the southern abutment was similar to the northern abutment movement.

The road surface on the north and south side of the of the bridge has also been periodically inspected to see if cracking in the asphalt surface at the end of the approach slab can be detected. On the morning of 30 July 2019 during a winter cold front, a crack measuring approximately $6 \mathrm{~mm}$ was measured on the southern side of the bridge. The shade temperature under the deck at the time of measurement was $2^{\circ} \mathrm{C}$ at approximately 9.00 a.m. This crack had opened up on the western side of the abutment approximately $4.1 \mathrm{~m}$ from the face of the abutment, which corresponded with the middle of the approach slab where the polyethylene sheet wrapping of the approach slab ended. Smaller cracks had opened up on the centreline

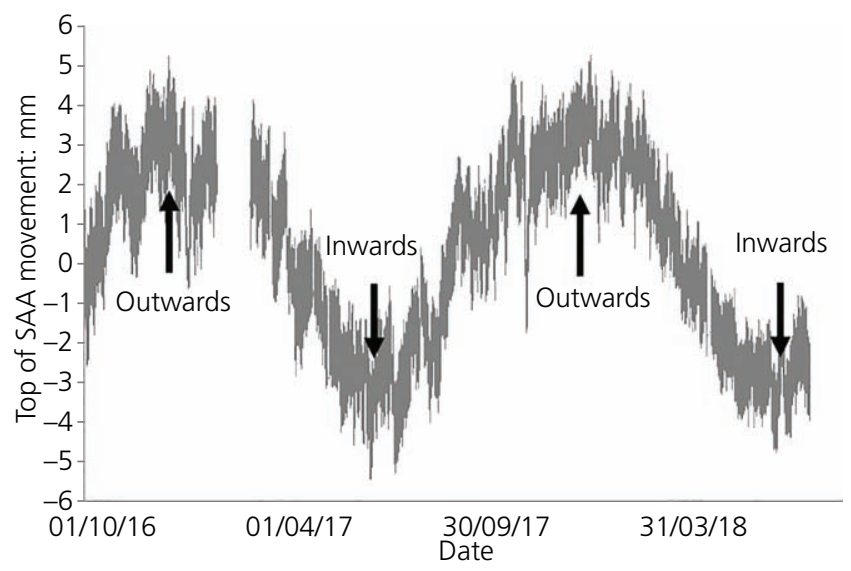

Figure 11. Relative top of north abutment movement from October 2016 to August 2018 
of the road, at a similar distance from the abutment. No cracking was seen at the north abutment, and no settlement of road has been observed. This observed cracking seemed to be consistent with the measured abutment movement. The cracks were subsequently sealed to prevent moisture ingress. The reason that no crack had opened up on the northern side was not clear at this point.

\section{Lateral earth pressure}

The seasonal change in temperature, causing the deck and abutment to extend outwards in the hotter summer months and inwards in the colder winter months, was reflected in the earth pressures measured from August 2016 (just after the backfill was completed) to June 2018. The earth pressure in summer increased linearly towards the base of the abutment wall; however, in winter, the earth pressure reduced significantly. This seasonal change in earth pressure has been observed in other integral bridges where earth pressures have been monitored (Barker and Carder, 2006; Darley et al., 1998).

There is a clear linear relationship between the effective bridge deck temperature and the lateral earth pressure, which is shown in Figure 12. An increase in the effective deck temperature, which caused an increase in the abutment movement, resulted in an increase in earth pressure as the deck pushes out into the earth fill. The readings from the earth pressure cells were referenced to a zero value in April 2016 before the backfilling began and temperature compensated, so that the readings from the backfill surcharge were taken into account.

The outwards abutment movement (i.e. into the fill) resulted in higher earth pressures, and an equivalent spring stiffness was calculated at each pressure cell by taking the ratio of the change in force (earth pressure multiplied by the tributary area) to abutment movement at the position of the pressure cell. This ratio or spring stiffness is shown in Table 4 for the positive (outwards) abutment movement.

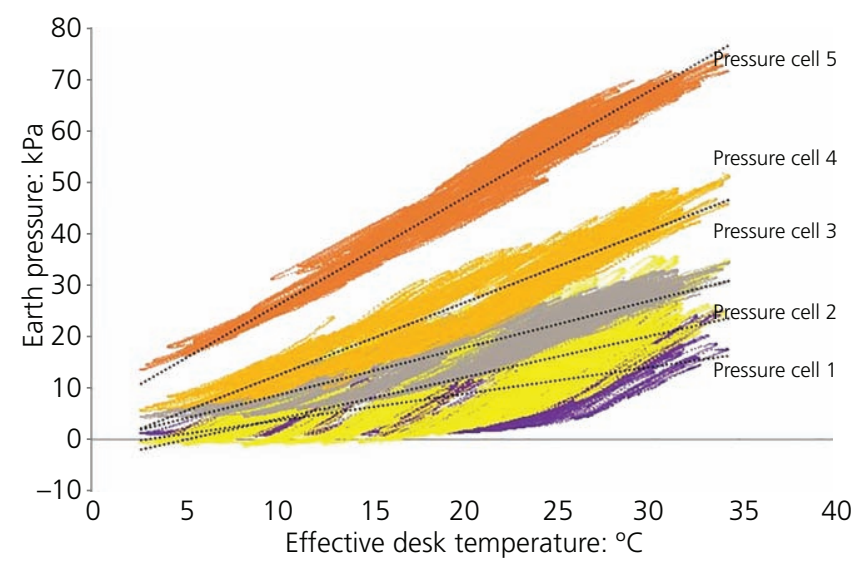

Figure 12. Effective deck temperature plotted against the north abutment earth pressure

\section{Calculated abutment movement}

To verify the effect of the thermal inertia of the deck on abutment movement, a two-dimensional structural model of the Van Zylspruit Bridge (half of the width) was set up. The deck, abutment and piles were modelled using elements with in-plane stiffness and material properties measured at Van Zylspruit. The soil behind the abutments was modelled with the linear spring stiffness calculated with the earth pressure and outwards abutment movement measured at Van Zylspruit (Table 4). It is acknowledged that in the real structure, this spring stiffness would vary when the deck contracts and the abutment moves inwards. Springs were also used to model the soil around the piles, which were embedded into rock. The end of the piles was assumed to be fixed. The self-weight of the structure was excluded from the model.

Using the measured seasonal effective deck temperature changes (for the 6-month range shown in Table 3), the predicted movement range at the abutment was modelled as shown in Table 5. The best match was obtained using the change in the effective temperature of the beam portion of the deck. This could be attributed to the fact that the flanges cracked over all the piers due to differential thermal loads and shrinkage. These cracks would mean that the thermal movement of the deck would be governed by the uncracked $1 \mathrm{~m}$ thick beam section, which varied in temperature seasonally by $29.1^{\circ} \mathrm{C}$. The movement of the top of abutment can thus be predicted by the change in the effective temperature of the uncracked portion of the deck. This calculation also shows that the predicted movement (using the recommended coefficient of thermal expansion of $12 \times$ $10^{-6} /{ }^{\circ} \mathrm{C}$ given in TMH7 (DOT, 1989) and the design seasonal change in the effective deck temperature of $48^{\circ} \mathrm{C}$ ) results in much higher abutment movements than that recorded.

It should be noted that the design range of effective deck temperatures must have some allowance for extreme situations, based on the lifespan of the bridge, which has not been measured during this monitoring project. The design temperature range would therefore be expected to be larger than the measured range.

Table 4. Calculated soil spring stiffness

\begin{tabular}{lcr}
$\begin{array}{l}\text { Pressure } \\
\text { cell }\end{array}$ & $\begin{array}{c}\text { Depth from top of } \\
\text { abutment: } \mathbf{m}\end{array}$ & $\begin{array}{c}\text { Soil spring stiffness: } \\
\mathbf{k N} / \mathbf{m}\end{array}$ \\
\hline 1 & 1.5 & 16667 \\
2 & 2.5 & 313000 \\
3 & 3.5 & 609333 \\
4 & 4.5 & 905667 \\
5 & 5.5 & 1202000 \\
\hline
\end{tabular}

Table 5. Predicted abutment movement

\begin{tabular}{lccc} 
& $\Delta \boldsymbol{T}:{ }^{\circ} \mathbf{C}$ & $\alpha$ range: $\times \mathbf{1 0 ^ { - 6 }} /{ }^{\circ} \mathbf{C}$ & $\Delta \mathbf{L}$ range: $\mathbf{~ m m}$ \\
\hline Deck & 30.2 & $8.5-9.75$ & $10.74-12.32$ \\
Beam & 29.1 & $8.5-9.75$ & $10.35-11.87$ \\
Flange & 33 & $8.5-9.75$ & $11.74-13.46$ \\
TMH7 (DOT, 1989) & 48 & 12 & 24.1
\end{tabular}




\section{Conclusions}

Measured temperature, movement and lateral earth pressure data obtained from a structural monitoring system at the Van Zylspruit Bridge are presented and discussed in this paper. The measured data proved valuable as these show the actual temperatures, movement and loads of an integral bridge structure. The data, as well as heat flow modelling, were used to confirm the effect of deck cross-section thermal inertia on the expansion of integral bridges. An increase in the cross-sectional area per unit width of the deck resulted in a lower change in the effective deck temperature and therefore smaller movement of the integral abutments. This trend is clearly seen with the measured data and confirms the research done by Emerson (1976) and Black et al. (1976). The measured behaviour of the Van Zylspruit Bridge confirms that an efficient design can be achieved if accurate effective deck temperatures are used to estimate the daily and seasonal changes in length and seasonal change in earth pressure behind integral bridge abutments.

This project has shown how valuable structural monitoring can be to designers as a means of calibrating design models and helping them better understand the behaviour of complex structures. Both the daily and seasonally measured data shown in Table 3, as well as the modelled daily temperature data shown in Figure 10, confirm that for a given set of bridge environmental conditions, longer integral bridges could be constructed, if careful consideration is given to the selection of a deck cross-section with a high thermal inertia as well as the measured coefficient of thermal expansion of the concrete (which takes the concrete aggregate into account). Deck cross-section profiles similar to the Van Zylspruit section (which vary in thickness) can be used effectively; however, to prevent cracking, attention should be paid to the detailing of passive secondary steel in restrained areas where the deck thickness changes.

\section{Acknowledgements}

The following organisations are gratefully acknowledged for their assistance during the course of the study:

- The South African National Roads Agency SOC Ltd

- Mott MacDonald PDNA

- Aveng Grinaker-LTA

- Dr A. Osam.

\section{REFERENCES}

Barker KJ and Carder DR (2006) Long Term Monitoring of Stresses behind Three Integral Bridge Abutments. Concrete Bridge Development Group, Camberley, UK, Technical Paper No. 10.

Black W, Moss DS and Emerson M (1976) Bridge Temperatures Derived from Measurement of Movement. Transport and Road Research Laboratory, Wokingham, UK, TRRL Report LR 748.

Branco FA and Mendes PA (1993) Thermal actions for concrete bridge design. Journal of Structural Engineering 119(8): 2313-2331.

Darley P, Carder DR and Baker KJ (1998) Seasonal Thermal Effects over Three Years on the Shallow Abutment of an Integral Bridge in Glasgow. Transport Research Laboratory, Wokingham, UK, TRL Report 344.
DOT (Department of Transport) (1989) TMH7:1989: Code of practice for the design of highway bridges and culverts in South Africa, Parts 1, 2 and 3. DOT, Pretoria, South Africa.

Elbadry M and Ghali A (1983) Temperature distributions in concrete bridges. Journal of Structural Engineering 109(10): 2355-2374.

Emerson M (1973) The Calculation of the Distribution of Temperature in Bridges. Transport and Road Research Laboratory, Wokingham, UK, TRRL Report LR 561.

Emerson M (1976) Bridge Temperatures Estimated from the Shade Temperature. Transport and Road Research Laboratory, Wokingham, UK, TRRL Report LR 696.

England GL, Tsang CM and Bush DI (2000) Integral Bridges: A Fundamental Approach to the Time-Temperature Loading Problem. Thomas Telford, London, UK.

Huang J, Sheild C and French C (2008) Parametric study of integral abutment bridges. Journal of Bridge Engineering 13(5): 511-526, https://doi.org/10.1061/ASCE1084-0702200813:5511.

Kim W and Laman JA (2010) Numerical analysis method for long-term behaviour of integral abutment bridges. Engineering Structures 32(8): 2247-2257, https://doi.org/10.1016/j.engstruct.2010.03.027.

LaFave JM, Riddle JK, Jarret MW et al. (2016) Numerical simulations of steel integral abutment bridges under thermal loading. Journal of Bridge Engineering 21(10): 1-17, https://doi.org/10.1061/(ASCE) BE. 1943-5592.0000919.

Larsson C and Svensson G (2013) Realistic Modelling of Thermal effects in Concrete Bridges. Lund University, Lund, Sweden, Report TVBK5223.

Petursson $\mathrm{H}$ and Kerokoski O (2013) Monitoring and analysis of abutment-soil interaction of two integral bridges. Journal of Bridge Engineering 18(1): 54-64, https://doi.org/10.1061/(ASCE)BE.19435592.0000314

Priestley MJN (1978) Design of concrete bridges for temperature gradients. ACI Structural Journal 75(5): 209-217, https://doi.org/10. 14359/10934.

Pugasap K, Kim W and Laman JA (2009) Long-term response prediction of integral abutment bridges. Journal of Bridge Engineering 14(2): 129-139, https://doi.org/10.1061/(ASCE)1084-0702(2009)14:2(129).

Robberts JM (2003) Behaviour of Integral Bridges Subject to Nonuniform Temperature Creep and Soil Structure Interaction Loading. $\mathrm{PhD}$ thesis, Imperial College of Science, Technology and Medicine, London, UK.

Roeder CW (2003) Proposed design method for thermal bridge movement. Journal of Bridge Engineering 8(1): 12-19, https://doi.org/ 10.1061/(ASCE)1084-0702(2003)8:1(12).

SABS (South African Bureau of Standards) (2000) SANS 50197-1:2000: Part 1: Composition, specifications and conformity criteria for common cements. SABS, Pretoria, South Africa.

\section{How can you contribute?}

To discuss this paper, please email up to 500 words to the editor at journals@ice.org.uk. Your contribution will be forwarded to the author(s) for a reply and, if considered appropriate by the editorial board, it will be published as discussion in a future issue of the journal.

Proceedings journals rely entirely on contributions from the civil engineering profession (and allied disciplines). Information about how to submit your paper online is available at www.icevirtuallibrary.com/page/authors, where you will also find detailed author guidelines. 